\title{
Genes involved in the regulation of vascular homeostasis determine renal survival rate in patients with chronic glomerulonephritis
}

\author{
Olga Litovkina a , Elena Nekipelova ${ }^{\mathrm{a}}$, Volodymyr Dvornyk ${ }^{\mathrm{b}}$, Alexey Polonikov ${ }^{\mathrm{c}}$, Olga Efremova ${ }^{\mathrm{a}}$, \\ Nina Zhernakova ${ }^{a}$, Evgeny Reshetnikov ${ }^{\mathrm{a}, *}$, Mikhail Churnosov ${ }^{\mathrm{a}}$ \\ a Institute of Medicine, Belgorod State National Research University, Belgorod, Russia \\ b School of Biological Sciences, University of Hong Kong, Hong Kong S.A.R., PR China \\ c Kursk State Medical University, Kursk, Russia
}

\section{A R T I C L E I N F O}

\section{Article history:}

Received 8 December 2013

Received in revised form 6 April 2014

Accepted 9 April 2014

Available online 13 April 2014

Keywords:

Chronic glomerulonephritis

Renal survival

Hypertension

Blood pressure

Gene polymorphism

\begin{abstract}
A B S T R A C T
Chronic glomerulonephritis (CGN) is one of the most severe kidney diseases. Genes of vascular reactivity are thought to play an important role in development and progression of CGN. In this study, we analyzed association of genes of vascular homeostasis with hypertension and renal survival of CGN patients. The study sample included 238 patients with CGN and 304 healthy subjects of population control. Ten polymorphisms of ten genes of vascular homeostasis were genotyped through polymerase chain reaction (PCR), restriction fragment length polymorphism (RFLP) analysis and TaqMan assays. Association of the genotypes with renal survival was analyzed by the Kaplan-Meier estimator. Genotypes 311SC and 311SS of the PON2 gene, $(-1166)$ AC and (-1166)CC of the AGTR1 gene, ( +46)AA of the ADRB2 gene, and 198KK and 198KN of the EDN1 gene were associated with decreased rate of renal survival of the patients. Polymorphisms S311C PON2, ( - 1166)A/C AGTR1, (+46)G/A ADRB2, and K198N EDN1 were associated with the accelerated decline in kidney function in the CGN patients.
\end{abstract}

(c) 2014 Published by Elsevier B.V.

\section{Introduction}

Chronic glomerulonephritis (CGN) is a genetically determined immune-mediated glomerular disease, which often associated with hypertension, and may result in renal failure and respective increased mortality (Nickolas et al., 2004). Genes of vascular homeostasis play an important role in development and progression of CGN. They regulate renal hemodynamics, mesangial cell proliferation, synthesis and degradation of extracellular matrix, and the rate of development of glomerulosclerosis (Egido, 1996; Jensen and Pedersen, 1997).

CGN often results in development of arterial hypertension ( $\mathrm{AH})$. There is a close relationship between hypertension and renal function (Best and Holmes, 2003). Impaired excretion of sodium and water by kidneys is considered as one of the main mechanisms of essential

Abbreviations: CGN, chronic glomerulonephritis; $\mathrm{AH}$, arterial hypertension; $\mathrm{BP}$, blood pressure; SBP, systolic blood pressure; DBP, diastolic blood pressure; GFR, glomerular filtration rate; DNA, deoxyribonucleic acid; SNP, single-nucleotide polymorphism; ACE, angiotensin I converting enzyme; NOS3, nitric oxide synthase 3; PON2, paraoxonase-2; AGT, angiotensinogen; AGTR1, angiotensin II receptor, type 1; EDN1, endothelin 1; CYP3A5, Cytochrome P450, Family 3, Subfamily A, Polypeptide 5; GNB3, guanine nucleotide binding protein (G Protein), beta polypeptide 3; ADD1, adducin 1 (alpha); ADRB2, adrenoceptor beta 2; PCR, polymerase chain reaction; HWE, Hardy-Weinberg equilibrium; Ors, odds ratios; CIs, 95\% confidence intervals; $\mathrm{p}_{\mathrm{c}}$, Bonferroni correction.

* Corresponding author at: Institute of Medicine, Belgorod State National Research University, 85 Pobeda St., Belgorod 308015, Russia.

E-mail address: resh.evgen@gmail.com (E. Reshetnikov). hypertension. In turn, essential hypertension contributes to kidney impairment through vasoconstriction, structural changes in renal arterioles, and parenchymal ischemia (Best and Holmes, 2003). Pathogenesis of arterial hypertension in renal disease is complex. One of the main factors is the activation of pressor hormone systems (sympathoadrenal system, renin-angiotensin-aldosterone system, endothelial constrictor hormones, endothelin). Therefore, genetic markers of these hormones have attracted an increased attention in recent years as possible risk factors for glomerulopathy (Buraczynska et al., 2006).

In this study, we examined polymorphisms of the genes of vascular homeostasis for their possible association with development of hypertension and renal survival in Russian patients suffering from CGN. The polymorphisms were selected on the basis of their possible contribution to pathogenesis of CGN and effect on expression of the genes. In particular, allele $\mathrm{D}$ at locus I/D of the $A C E$ gene confers higher expression to the enzyme than allele I (Ueda et al., 1996). Allele ( -6$)$ A of the AGT gene is associated with higher expression of angiotensinogen (Brand et al., 2000). The ( -1166$) \mathrm{A} / \mathrm{C}$ polymorphism of the AGTR1 gene is known to alter the structure of a cis-element within the gene that increases gene expression (Wang et al., 2006). Homozygotes 4a4a of the NOS3 gene have lower activity of the enzyme as compared to the $4 \mathrm{~b} 4 \mathrm{~b}$ homozygotes (Dosenko et al., 2006). Allele (+6986)A of the CYP3A5 gene is associated with increased expression of the respective enzyme (Givens et al., 2003). Importantly, the above polymorphisms have been associated with the risk of hypertension in various diseases (Calle et al., 2006; Misono et al., 2009; Tiret et al., 1999). 


\section{Methods}

\subsection{Subjects}

The study protocol was approved by the Ethics Committee of Belgorod State National Research University. All subjects signed an informed consent before entering the study. In total 542 subjects, including 238 patients with CGN and 304 individuals of population control, were recruited for this study. All study subjects were unrelated Russians from Central Chernozem Region of Russia (Belgorod). Patients were enrolled in the case group only after the clinically confirmed diagnosis of CGN. Clinical and laboratory examination of patients was conducted at the Nephrology Clinic of Belgorod Regional Clinical Hospital.

Blood samples were taken during the period of the patient's hospitalization. The patients were examined monthly by a nephrologist for the period of 6 months to 1 year. Blood pressure (BP) level was measured daily in the morning, in the upper-sitting position of the patient. At least 3 measurements were made and the average systolic blood pressure (SBP) and diastolic blood pressure (DBP) were calculated. $\mathrm{SBP} \geq 140 \mathrm{~mm} \mathrm{Hg}$ and/or DBP $\geq 90 \mathrm{~mm} \mathrm{Hg}$ were considered as an indication of $\mathrm{AH}$. BP $\geq 160 / 100 \mathrm{~mm} \mathrm{Hg}$ in patients taking antihypertensive drugs was considered as an indicator of severe course of AH. The exclusion criteria for the CGN patients were the history of diabetes mellitus or hypertension.

Renal survival in patients with CGN was assessed in a group of 138 individuals with non-terminal renal failure. Of these, 104 patients had normal renal function (creatinine level $<140 \mu \mathrm{mol} / \mathrm{l}$ ) and 34 patients had chronic renal failure (creatinine level was $140 \mu \mathrm{mol} / \mathrm{l}$ during 6 months of observation). The progress of chronic renal failure was analyzed from the onset of the disease. The endpoint of the observation was doubling of baseline creatinine. Renal function was assessed through glomerular filtration rate (GFR) which was estimated by Cockroft-Gault's formula (Cockcroft and Gault, 1976).

\subsection{DNA isolation}

Genomic DNA was isolated from $10 \mathrm{ml}$ of whole blood using a method proposed by Miller et al. (1988).

\subsection{Genotyping}

The ten DNA polymorphisms were genotyped through the analysis of amplified fragment length polymorphism (I/D polymorphism of the ACE gene, VNTR polymorphism of the NOS3 gene), the analysis of restriction fragment length polymorphisms (S311C of the PON2 gene (rs7493), $-6 \mathrm{~A} / \mathrm{G}$ the AGT gene (rs5051), $-1166 \mathrm{~A} / \mathrm{C}$ of the AGTR1 gene (rs5186)) and Tag-Man allele discrimination analysis (K198N of the EDN1 gene (rs5370), +6986G/A of the CYP3A5 gene (rs776746), $\mathrm{G} / \mathrm{A}$ (rs2301339) of the GNB3 gene (rs2301339), G460W of the ADD1 gene, $+46 \mathrm{G} / \mathrm{A}$ of the ADRB2 gene (rs1042713)). The structure of the primers and PCR conditions for genotyping the DNA polymorphisms are described in detail elsewhere (Agerholm-Larsen et al., 2000; Asai et al., 2001; Jalilian et al., 2008; Lanfear et al., 2005; Picard et al., 2007; Prasad et al., 2006; Yazdanpanah et al., 2007).

\subsection{Statistical analysis}

The allele frequencies were checked for departures from the HardyWeinberg equilibrium (HWE) using the chi-square test. Association of the DNA markers with CGN in hypertensive patients was assessed through the chi-square test with Yates' correction. Odds ratios (ORs) and 95\% confidence intervals (CIs) were used to estimate the association between the polymorphisms and the risk of CGN in the hypertensive patients. The calculations were adjusted for multiple testing by Bonferroni correction $\left(\mathrm{p}_{\mathrm{c}}\right)$.
Table 1

Characteristics of the subjects from the case and control groups.

\begin{tabular}{lll}
\hline Characteristics & Cases & Controls \\
\hline Total & 238 & 304 \\
Males & $127(53.4 \%)^{*}$ & $164(53.9 \%)$ \\
Females & $111(46.6 \%)^{*}$ & $140(46.1 \%)$ \\
Age, years & $39.58 \pm 14.58^{*}$ & $42.20 \pm 6.28$ \\
Weight, kg & $63.4 \pm 2.1^{*}$ & $67.4 \pm 1.7$ \\
Height, cm & $165.4 \pm 3.4^{*}$ & $168.6 \pm 2.7$ \\
SBP, mm Hg & $148.4 \pm 26.5^{* *}$ & $128.1 \pm 4.4$ \\
DBP, mm Hg & $92.7 \pm 14.0^{* *}$ & $82.2 \pm 2.0$ \\
Creatinine, $\mu \mathrm{mol} / \mathrm{l}$ & $337.2 \pm 44.1^{* *}$ & $130.4 \pm 7.8$ \\
GFR, ml/min & $28.2 \pm 1.8$ & $81.6 \pm 3.4$ \\
\hline$* \mathrm{p}>0.05$. & & \\
$* * \mathrm{p}<0.001$. & & \\
& &
\end{tabular}

The patients were divided into three groups according to their BP: below 140/90 $\mathrm{mm} \mathrm{Hg}$ (the first group, 84 patients, 36.2\%), from $140 / 90$ to $159 / 100 \mathrm{~mm} \mathrm{Hg}$ (the second group, 96 patients, $41.4 \%$ ), and above $160 / 110 \mathrm{~mm} \mathrm{Hg}$ (the third group, 52 patients, 22.4\%).

Association of renal survival with the genotypes was analyzed using the Kaplan-Meier test. A software package STATISTICA for Windows v. 6.0 (StatSoft, Inc.) was used for the analyses.

\section{Results}

The average age of the CGN patients and the population control subjects was similar $(39.58 \pm 14.58$ years and $42.20 \pm 6.28$ years, respectively, $\mathrm{p}>0.05)$. The main characteristics of the study subjects are shown in Table 1 . Notably, patients with CGN had higher levels of both systolic (148.4 $\pm 26.5 \mathrm{~mm} \mathrm{Hg}$ ) and diastolic $(92.7 \pm 14.0 \mathrm{~mm} \mathrm{Hg})$ blood pressures as compared to the control group ( $\mathrm{p}<0.001$ ). As shown in Table 1 , creatinine level in patients with CGN was $337.2 \pm 44.1 \mu \mathrm{mol} / \mathrm{l}$, significantly higher than that in the control group $(\mathrm{p}<0.001)$. Glomerular filtration rate in CGN patients was $28.2 \pm 1.8 \mathrm{ml} / \mathrm{min}$, which was significantly lower than that in the control group $(\mathrm{p}<0.001)$.

All studied DNA polymorphisms (except G460W of the ADD1 gene, $\mathrm{p}<0.05$ ) showed no deviation from the HWE (Table 2 ).

No statistically significant differences in allele and genotype frequencies were found between the CGN patients and the controls $(\mathrm{p}>0.05)$.

Table 2

Summary information about the studied polymorphisms.

\begin{tabular}{|c|c|c|c|c|c|}
\hline \multirow[t]{2}{*}{ Polymorphism } & \multirow{2}{*}{$\begin{array}{l}\text { Studied } \\
\text { groups }\end{array}$} & \multirow[t]{2}{*}{ Minor allele } & \multirow[t]{2}{*}{ MAF (\%) } & \multicolumn{2}{|l|}{ HWE } \\
\hline & & & & $\chi^{2}$ & $\mathrm{p}$ \\
\hline $\mathrm{I} / \mathrm{D} A C E$ & Case & I $A C E$ & 45.09 & 0.87 & $>0.05$ \\
\hline $\mathrm{I} / \mathrm{D} A C E$ & Control & I $A C E$ & 48.18 & 0.19 & $>0.05$ \\
\hline $4 \mathrm{a} / 4 \mathrm{~b}$ NOS3 & Case & 4a NOS3 & 21.37 & 0.26 & $>0.05$ \\
\hline 4a/4b NOS3 & Control & 4a NOS3 & 19.50 & 0.90 & $>0.05$ \\
\hline S311C PON2 & Case & 311C PON2 & 24.58 & 0.17 & $>0.05$ \\
\hline S311C PON2 & Control & 311C PON2 & 28.12 & 0.75 & $>0.05$ \\
\hline$(-6) \mathrm{A} / \mathrm{G} A G T$ & Case & $(-6) G A G T$ & 48.11 & 0.06 & $>0.05$ \\
\hline$(-6) \mathrm{A} / \mathrm{G} A G T$ & Control & $(-6) G A G T$ & 47.69 & 1.38 & $>0.05$ \\
\hline$(-1166) \mathrm{A} / \mathrm{C}$ AGTR1 & Case & $(-1166) C$ AGTR1 & 26.18 & 1.01 & $>0.05$ \\
\hline$(-1166) \mathrm{A} / \mathrm{C}$ AGTR1 & Control & $(-1166) C$ AGTR1 & 25.99 & 0.19 & $>0.05$ \\
\hline G/A GNB3 & Case & A GNB3 & 34.18 & 0.24 & $>0.05$ \\
\hline G/A GNB3 & Control & A GNB3 & 31.68 & 0.41 & $>0.05$ \\
\hline G460W ADD1 & Case & 460W ADD1 & 16.31 & 13.55 & $<0.001$ \\
\hline G460W ADD1 & Control & 460W ADD1 & 15.13 & 1.84 & $>0.05$ \\
\hline$(+46) \mathrm{G} / \mathrm{A} A D R B 2$ & Case & $(+46) \mathrm{A} A D R B 2$ & 36.86 & 2.01 & $>0.05$ \\
\hline$(+46) \mathrm{G} / \mathrm{A} A D R B 2$ & Control & $(+46) \mathrm{A} A D R B 2$ & 39.93 & 1.26 & $>0.05$ \\
\hline K198N EDN1 & Case & 198N EDN1 & 17.02 & 0.30 & $>0.05$ \\
\hline K198N EDN1 & Control & 198N EDN1 & 18.54 & 0.38 & $>0.05$ \\
\hline$(+6986)$ G/A CYP3A5 & Case & $(+6986)$ А СУРЗА5 & 7.48 & 1.53 & $>0.05$ \\
\hline 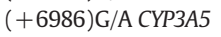 & Control & $(+6986)$ А СУРЗА5 & 5.92 & 0.93 & $>0.05$ \\
\hline
\end{tabular}

Notes: MAF, minor allele frequency; HWE, Hardy-Weinberg equilibrium. p values were calculated using the $\chi^{2}$ test. 
Table 3

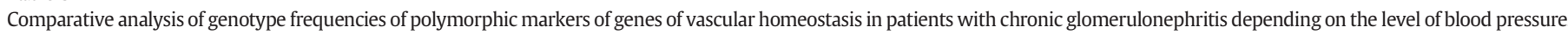

\begin{tabular}{|c|c|c|c|c|c|c|c|c|c|c|c|}
\hline \multirow[t]{3}{*}{ Locus } & \multirow[t]{3}{*}{ Genotype } & \multirow{3}{*}{$\begin{array}{l}\text { Controls } \\
(\mathrm{n}=304) \\
1 \\
\mathrm{n}(\%)\end{array}$} & \multicolumn{3}{|c|}{ Blood pressure $(\mathrm{mm} \mathrm{Hg})$} & \multicolumn{6}{|c|}{ Difference, p } \\
\hline & & & \multirow{2}{*}{$\begin{array}{l}<140 / 90 \\
(\mathrm{n}=84) \\
2 \\
\mathrm{n}(\%)\end{array}$} & \multirow{2}{*}{$\begin{array}{l}140 / 90-159 / 99 \\
(\mathrm{n}=96) \\
3 \\
\mathrm{n}(\%)\end{array}$} & \multirow{2}{*}{$\begin{array}{l}>160 / 100 \\
(\mathrm{n}=52) \\
4 \\
\mathrm{n}(\%)\end{array}$} & \multirow[b]{2}{*}{$1-2$} & \multirow[b]{2}{*}{$1-3$} & \multirow[b]{2}{*}{$1-4$} & \multirow[b]{2}{*}{$2-3$} & \multirow[b]{2}{*}{$2-4$} & \multirow[b]{2}{*}{$3-4$} \\
\hline & & & & & & & & & & & \\
\hline \multirow[t]{3}{*}{ I/D ACE } & II & $72(23.84)$ & $14(17.07)$ & $18(18.95)$ & $10(19.61)$ & 0.25 & 0.39 & 0.63 & 0.90 & 0.89 & 1.00 \\
\hline & ID & $147(48.68)$ & $45(54.88)$ & $46(48.42)$ & $29(56.86)$ & 0.38 & 1.00 & 0.35 & 0.48 & 0.97 & 0.43 \\
\hline & DD & $83(27.48)$ & $23(28.05)$ & $31(32.63)$ & $12(23.53)$ & 1.00 & 0.40 & 0.68 & 0.62 & 0.71 & 0.34 \\
\hline \multirow[t]{3}{*}{$4 \mathrm{a} / 4 \mathrm{~b}$ NOS3 } & $4 a 4 a$ & $14(4.67)$ & $6(7.32)$ & $6(6.38)$ & $0(0.00)$ & 0.50 & 0.70 & 0.23 & 1.00 & 0.12 & 0.16 \\
\hline & $4 a 4 b$ & 89 (29.67) & $21(25.61)$ & $35(37.23)$ & $19(36.54)$ & 0.56 & 0.21 & 0.41 & 0.14 & 0.25 & 1.00 \\
\hline & $4 \mathrm{~b} 4 \mathrm{~b}$ & $197(65.66)$ & $55(67.07)$ & $53(56.38)$ & $33(63.46)$ & 0.92 & 0.13 & 0.88 & 0.20 & 0.81 & 0.51 \\
\hline \multirow[t]{3}{*}{ S311C PON2 } & $311 C C$ & $21(6.91)$ & $3(3.62)$ & $8(8.42)$ & $1(1.92)$ & 0.40 & 0.79 & 0.29 & 0.31 & 0.97 & 0.23 \\
\hline & $311 S C$ & $129(42.43)$ & 36 (43.37) & $30(31.58)$ & $22(42.31)$ & 0.98 & 0.08 & 1.00 & 0.14 & 1.00 & 0.26 \\
\hline & 311SS & $154(50.66)$ & $44(53.01)$ & $57(60.00)$ & $29(55.77)$ & 0.80 & 0.14 & 0.60 & 0.43 & 0.89 & 0.75 \\
\hline \multirow[t]{3}{*}{$(-6) \mathrm{A} / \mathrm{G} A G T$} & $(-6) \mathrm{AA}$ & $92(30.36)$ & $29(34.94)$ & 19 (19.79) & $14(26.92)$ & 0.51 & 0.06 & 0.74 & 0.04 & 0.43 & 0.43 \\
\hline & $(-6) A G$ & $136(44.89)$ & $34(40.96)$ & $58(60.42)$ & $27(51.92)$ & 0.61 & 0.01 & 0.43 & 0.02 & 0.44 & 0.41 \\
\hline & $(-6) \mathrm{GG}$ & 75 (24.75) & $20(24.10)$ & 19 (19.79) & $11(21.16)$ & 0.94 & 0.39 & 0.70 & 0.61 & 0.85 & 1.00 \\
\hline \multirow[t]{3}{*}{$(-1166) \mathrm{A} / \mathrm{C}$ AGTR1 } & $(-1166) \mathrm{AA}$ & $168(55.26)$ & $38(46.34)$ & $54(57.45)$ & $27(52.94)$ & 0.19 & 0.80 & 0.88 & 0.19 & 0.57 & 0.73 \\
\hline & $(-1166) A C$ & $114(37.50)$ & $41(50.00)$ & $33(35.11)$ & $21(41.18)$ & 0.05 & 0.77 & 0.73 & 0.07 & 0.42 & 0.59 \\
\hline & $(-1166) \mathrm{CC}$ & $22(7.24)$ & $3(3.66)$ & $7(7.45)$ & $3(5.88)$ & 0.36 & 1.00 & 0.96 & 0.45 & 0.87 & 0.99 \\
\hline \multirow[t]{3}{*}{ G/A GNB3 (rs2301339) } & GG & $139(45.88)$ & $34(40.96)$ & 40 (41.67) & $23(44.23)$ & 0.50 & 0.55 & 0.95 & 1.00 & 0.85 & 0.90 \\
\hline & GA & $136(44.88)$ & $38(45.78)$ & $48(50.00)$ & $22(42.31)$ & 0.98 & 0.44 & 0.85 & 0.68 & 0.83 & 0.47 \\
\hline & $\mathrm{AA}$ & $28(9.24)$ & $11(13.26)$ & $8(8.33)$ & $7(13.46)$ & 0.39 & 0.95 & 0.49 & 0.41 & 0.55 & 0.48 \\
\hline G460W & 460WW & $10(3.29)$ & $6(7.23)$ & $6(6.26)$ & $2(3.92)$ & 0.20 & 0.32 & 1.00 & 1.00 & 0.68 & 0.83 \\
\hline \multirow[t]{2}{*}{$A D D 1$} & 460GW & $72(23.68)$ & $12(14.46)$ & $35(26.04)$ & $12(23.53)$ & 0.10 & 0.74 & 1.00 & 0.08 & 0.27 & 0.89 \\
\hline & 460GG & $222(73.03)$ & $65(78.31)$ & $65(67.71)$ & $37(72.55)$ & 0.41 & 0.38 & 1.00 & 0.16 & 0.58 & 0.68 \\
\hline$(+46)$ & $(+46) \mathrm{GG}$ & $114(37.62)$ & $30(36.14)$ & 39 (41.05) & $18(34.61)$ & 0.91 & 0.63 & 0.80 & 0.61 & 1.00 & 0.56 \\
\hline $\mathrm{G} / \mathrm{A}$ & $(+46) \mathrm{GA}$ & $136(44.88)$ & $43(51.81)$ & $45(47.37)$ & $28(53.85)$ & 0.32 & 0.80 & 0.30 & 0.61 & 0.96 & 0.52 \\
\hline ADRB2 & $(+46) \mathrm{AA}$ & $53(17.50)$ & $10(12.05)$ & $11(11.58)$ & $6(11.54)$ & 0.31 & 0.23 & 0.39 & 1.00 & 1.00 & 1.00 \\
\hline K198N & $198 \mathrm{KK}$ & 202 (66.89) & 59 (71.08) & 61 (64.89) & $38(73.08)$ & 0.55 & 0.82 & 0.47 & 0.47 & 0.96 & 0.41 \\
\hline \multirow[t]{2}{*}{ EDN1 } & $198 \mathrm{KN}$ & $88(29.14)$ & 19 (22.89) & $30(31.91)$ & $14(26.92)$ & 0.32 & 0.71 & 0.87 & 0.24 & 0.75 & 0.66 \\
\hline & $198 \mathrm{NN}$ & $12(3.97)$ & $5(6.03)$ & $3(3.20)$ & $0(0.00)$ & 0.61 & 0.97 & 0.30 & 0.59 & 0.18 & 0.49 \\
\hline$(+6986)$ & $(+6986) \mathrm{GG}$ & $270(88.81)$ & $72(87.80)$ & $79(84.04)$ & $42(80.77)$ & 0.95 & 0.29 & 0.16 & 0.62 & 0.39 & 0.79 \\
\hline $\mathrm{G} / \mathrm{A}$ & $(+6986) \mathrm{GA}$ & $32(10.53)$ & $10(12.20)$ & 15 (15.96) & $10(19.23)$ & 0.82 & 0.21 & 0.12 & 0.62 & 0.39 & 0.79 \\
\hline СУРЗА5 & $(+6986) \mathrm{AA}$ & $2(0.66)$ & $0(0.00)$ & $0(0.00)$ & $0(0.00)$ & 1.00 & 1.00 & 1.00 & 1.00 & 1.00 & 1.00 \\
\hline
\end{tabular}

The results of the association analysis of the polymorphisms with the BP level in the CGN patients are shown in Table 3. No significant association was detected between the polymorphisms and blood pressure level. Then a subgroup of 138 CGN patients (68 men and 70 women) was used to perform the survival analysis. Thirty four patients had a doubling of baseline creatinine. The average age of these patients was $41.53 \pm 1.31$ years, duration of the disease was $9.87 \pm 0.85$ years.

The accelerated decline in renal function (early development of chronic kidney failure) was significantly associated with the genotypes of the four polymorphisms (Figs. 1-4). In particular, genotypes 311SC and 311SS of the PON2 gene (Fig. 1), (-1166)AC and (-1166)CC of

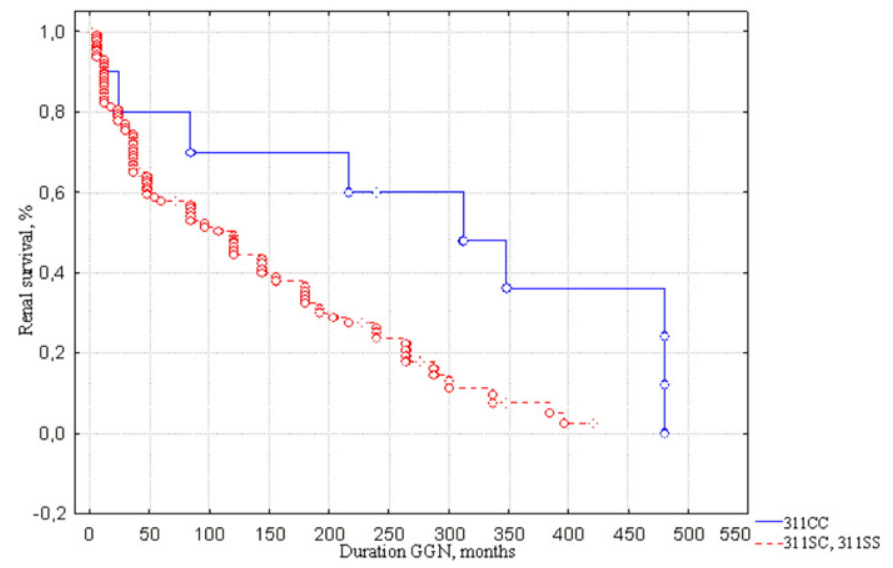

Fig. 1. Renal survival of CGN patients with different genotypes of the $S 311 \mathrm{C}$ polymorphism of the PON2 gene. Genotypes 311SS and 311SC PON2 are marked by dashed line, genotype $311 C C$ PON2 is marked by full line. All differences are significant $(p=0.05)$. Renal survival is expressed in months. the AGTR1 gene (Fig. 2), (+46)AA of the ADRB2 gene (Fig. 3), and 198KK and 198KN of the EDN1 gene (Fig. 4) were found to be associated with renal failure survival in patients suffering from CGN.

\section{Discussion}

Genes of vascular homeostasis have traditionally been a subject of interest. Some mutations in these genes alter their expression level, which, in turn, may affect the development of chronic inflammatory process. However, the data about the role of individual polymorphisms

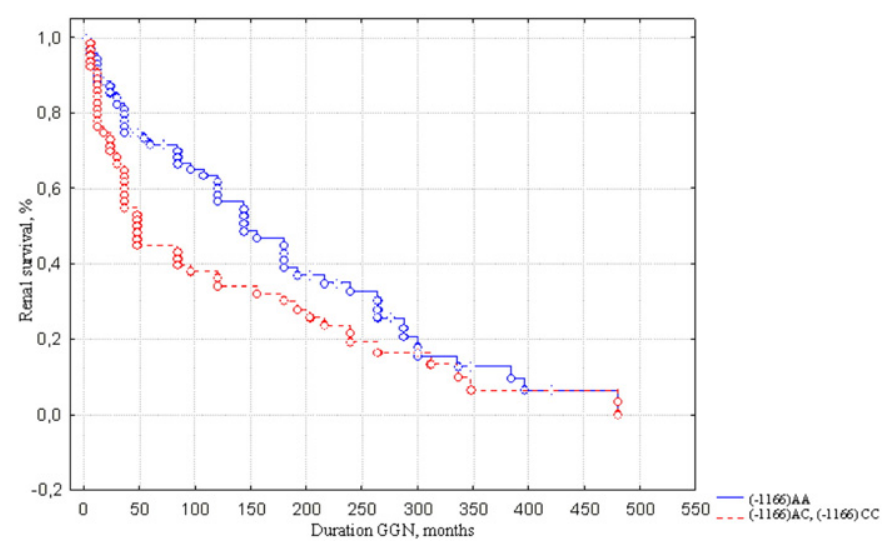

Fig. 2. Renal survival of CGN patients with different genotypes of the $(-1166) A / C$ polymorphism of the AGTR1 gene. Genotypes (-1166)AC and (-1166)CC AGTR1 are marked by dashed line, genotype ( -1166$)$ AA AGTR1 is marked by full line. All differences are significant $(\mathrm{p}=0.008)$. Renal survival is expressed in months. 


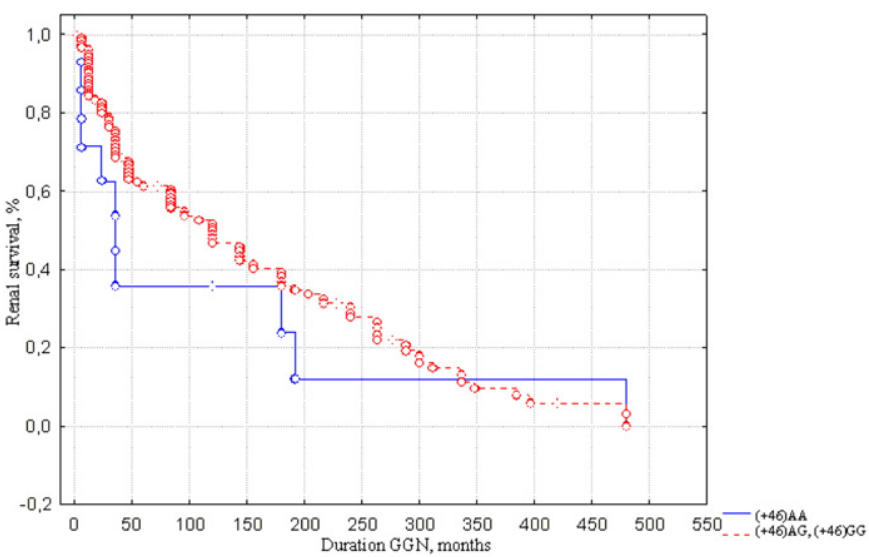

Fig. 3. Renal survival of CGN patients with different genotypes of the $(+46) \mathrm{G} / \mathrm{A}$ polymorphism of the ADRB2 gene. Genotype (+46)AA ADRB2 is marked by full line, genotypes $(+46) \mathrm{AA}$ and $(+46) \mathrm{GG}$ ADRB2 are marked by dashed line. All differences are significant $(\mathrm{p}=0.05)$. Renal survival is expressed in months.

of genes of vascular homeostasis in the progression of the kidney disease are often inconsistent (Buraczynska et al., 2006).

An important role of hemodynamic disorders (including those associated with arterial hypertension) in the progression of nephropathy has been supported by other studies (Brown and Whitworth, 1992; Losito et al., 2003). The relationship between pathological processes in kidneys and the development of arterial hypertension is ambilateral. On the one hand, renal pathology itself may cause hypertension, on the other hand, kidney function depends on the blood pressure level. In CGN, glomeruli, which survived after the initial injury, undergo adaptive changes in order to compensate the loss of functional renal tissue. Increased glomerular function is associated with significant changes in renal hemodynamics, such as increased perfusion of the remaining nephrons, the development of intraglomerular hypertension and renal hyperfiltration (Best and Holmes, 2003).

Here we determined genetic factors, which may reduce renal survival. Two genotypes of the EDN1 gene K198N polymorphism, 198KK and $198 \mathrm{KN}$, were associated with impaired renal function. Similar results were obtained by Fei-Fei et al. (2008) who reported a decline in renal function and the lower survival rate in carriers of the 198KK genotype. Like angiotensin-II, endothelin-1 is a growth factor contributing to the increased production of extracellular matrix by fibroblasts, mesangial and epithelial cells and, therefore, may take part in the development of glomerulosclerosis.

The observed associations of the AGTR1 variants with decreased renal survival in the CGN patients may be related to the vasoconstrictor effect of the respective protein (Wang et al., 2006), which is apparently

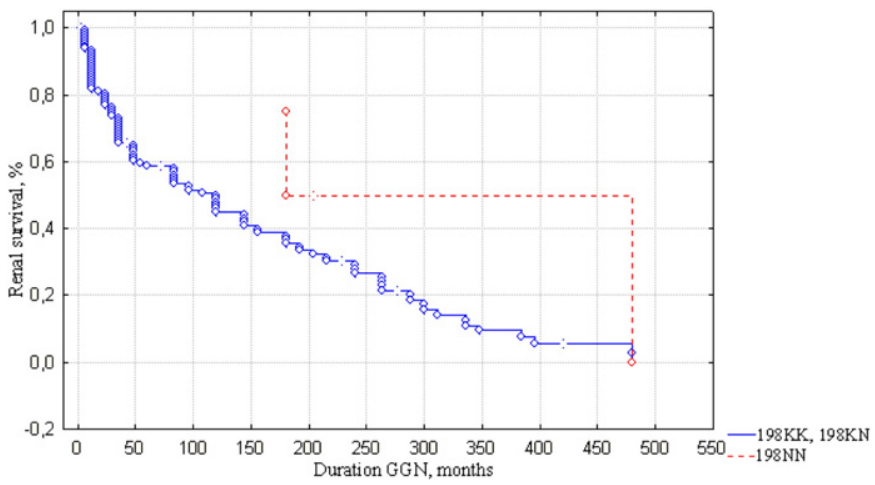

Fig. 4. Renal survival of CGN patients with different genotypes of the K198N polymorphism of the EDN1 gene. Genotypes 198KK and 198KN EDN1 are marked by full line, genotype 198NN EDN1 is marked by dashed line. All differences are significant $(\mathrm{p}=0.05$ ) Renal survival is expressed in months. more pronounced in the patients with high-yielding allele $(-1166) \mathrm{C}$. Previously Buraczynska et al. (2006) found that the average time of the end stage renal disease was significantly shorter in patients with genotypes $(-1166) A C$ and $(-1166) C C$ than in those with genotype (-1166)AA.

A number of studies showed association of the $(+46) \mathrm{G} /$ A polymorphism in the ADRB2 gene with hypertension (Masuo et al., 2005; Misono et al., 2009). We found that genotype AA of this SNP confers lower renal survival to the CGN patients. Elevated expression of $\beta 2$-adrenoceptor in the juxtaglomerular apparatus of kidneys results in the increased release of renin and, consequently, activation of the renin-angiotensin-aldosterone system. The main player in this system, angiotensin II, causes both systemic and kidney-specific local spasm of arterioles and an associated increase in both total peripheral vascular resistance and renal vascular resistance, elevates sodium reabsorption by acting directly on renal tubules, and stimulates renal hypertrophy and proteinuria.

\section{Conclusions}

The results of the present study suggest that genotypes 311SC and $311 \mathrm{SS}$ of the PON2 gene, $(-1166)$ AC and $(-1166)$ CC of the AGTR1 gene, (+46)AA of the ADRB2 gene, and 198KK and 198KN of the EDN1 may contribute to renal function decline.

\section{Conflict of interest}

The authors declare that they have no conflicts of interest.

\section{Acknowledgments}

The study was supported by the project "Studying of the genetic risk factors for multifactorial diseases" (state contract number 511/2014).

\section{References}

Agerholm-Larsen, B., Nordestgaard, B.G., Tybjaerg-Hansen, A., 2000. ACE gene polymorphisms in cardiovascular disease: metaanalysis of small and large studies in whites. Arteriosclerosis, Thrombosis, and Vascular Biology 20, 484-492.

Asai, T., Ohkubo, T. Katsuya, T. et al., 2001. Endothelin-1 gene variant associates with blood pressure in obese Japanese subjects. Journal of Hypertension 38, 1321-1324.

Best, P.J., Holmes, D.R., 2003. Chronic kidney disease as a cardiovascular risk factor. Journal of Human Hypertension 145, 383-385.

Brand, E., Ringel, J., Sharma, A.M., 2000. Role of the angiotensinogen gene for essential hypertension. Herz 25, 15-25.

Brown, M.A., Whitworth, J.A., 1992. Hypertension in human renal disease. Journal of Hypertension 10, 701-712.

Buraczynska, M., Ksiazek, P., Drop, A., Zaluska, W., Spasiewicz, D., Ksiazek, A., 2006. Genetic polymorphisms of the renin-angiotensin system in end-stage renal disease. Nephrology, Dialysis, Transplantation 21, 979-983.

Calle, R., McCarthy, M.I., Banerjee, P., Zeggini, E., Cull, C.A., Thorne, K.I., et al., 2006. Paraoxonase 2 (PON2) polymorphisms and development of renal dysfunction in type 2 diabetes. Diabetologia 49, 2892-2899.

Cockcroft, D.W., Gault, M.H., 1976. Prediction of creatinine clearance from serum creatinine. Nephron 16, 31-41.

Dosenko, V.E., Zagoriy, V.Y., Haytovich, N.V., Gordok, O.A., Moibenko, A.A., 2006. Allelic polymorphism of endothelial NO-synthase gene and its functional manifestations. Acta Biochimica Polonica 53, 299-302.

Egido, J., 1996. Vasoactive hormones and renal sclerosis. Kidney International 49, 578-597.

Fei-Fei, Y., Noriko, S., Ichiei, N., Takayoshi, M., et al., 2008. Endothelin-1 K198N polymorphism modifies clinical and histopathological manifestations of IgA nephropathy. Acta Medica et Biologica 56, 11-17.

Givens, R.C., Lin, Y.S., Dowling, A.L., et al., 2003. CYP3A5 genotype predicts renal CYP3A activity and blood pressure in healthy adults. Journal of Applied Physiology 95, 1297-1300.

Jalilian, A., Javadi, E., Akrami, M., et al., 2008. Association of Cys 311 Ser polymorphism of paraoxonase-2 gene with the risk of coronary artery disease. Archives of Iranian Medicine 11, 544-549.

Jensen, L.W., Pedersen, E.B., 1997. Nocturnal blood pressure and relation to vasoactive hormones and renal function in hypertension and chronic renal failure. Blood Pressure 6, 332-342.

Lanfear, D.E., Jones, P.G., Marsh, S., Cresci, S., McLeod, H.L., Spertus, J.A., 2005. ß2Adrenergic receptor genotype and survival among patients receiving $\beta$-blocker therapy after an acute coronary syndrome. JAMA 294, 1526-1533. 
Losito, A., Kalidas, K., Santoni, S., Jeffery, S., 2003. Association of interleukin-6 -174G/C promoter polymorphism with hypertension and left ventricular hypertrophy in dialysis patients. Kidney International 64, 616-622.

Masuo, K., Katsuya, T., Fu, Y., Rakugi, H., Ogihara, T., Tuck, M.L., 2005. Beta2- and beta3adrenergic receptor polymorphisms are related to the onset of weight gain and blood pressure elevation over 5 years. Circulation 11, 3429-3434.

Miller, S.A., Dykes, D.D., Polesky, H.F., 1988. A simple salting out procedure for extracting DNA from human nucleated cells. Nucleic Acids Research 16, 1215

Misono, M., Maeda, S., Iemitsu, M., Nakata, Y., Otsuki, T., Sugawara, J., et al., 2009. Combination of polymorphisms in the [beta]2-adrenergic receptor and nitric oxide synthase 3 genes increases the risk for hypertension. Journal of Hypertension 27, 1377-1383.

Nickolas, T.L., Frisch, G.D., Opotowsky, A.R., Arons, R., Radhakrishnan, J., 2004. Awareness of kidney disease in the US population: findings from the National Health and Nutrition Examination Survey (NHANES) 1999 to 2000. American Journal of Kidney Diseases 44, 185-197.

Picard, N., Djebli, N., Sauvage, F.L., Marquet, P., 2007. Metabolism of sirolimus in the presence or absence of cyclosporine by genotyped human liver microsomes and recombinant cytochromes P450 3A4 and 3A5. Drug Metabolism and Disposition 35, 350-355.
Prasad, P., Tiwari, A.K., Kumar, K.M., et al., 2006. Chronic renal insufficiency among Asian Indians with type 2 diabetes: I. Role of RAAS gene polymorphisms. BMC Medical Genetics 7, 42.

Tiret, L., Poirier, O., Hallet, V., et al., 1999. The Lys198Asn polymorphism in the endothelin1 gene is associated with blood pressure in overweight people. Journal of Hypertension 33, 1169-1174.

Ueda, S., Heeley, R.P., Lees, K.R., Elliott, H.L., Connell, J.M., 1996. Mistyping of the human angiotensin-converting enzyme gene polymorphism: frequency, causes and possible methods to avoid errors in typing. Journal of Molecular Endocrinology 17, 27-30.

Wang, X., Zhu, H., Dong, Y., Treiber, F.A., Snieder, H., 2006. Effects of angiotensinogen and angiotensin II type I receptor genes on blood pressure and left ventricular mass trajectories in multiethnic youth. Journal of Human Genetics 9, 393-402.

Yazdanpanah, M., Aulchenko, Y.S., Hofman, A., et al., 2007. Effects of the renin-angiotensin system genes and salt sensitivity genes on blood pressure and atherosclerosis in the total population and patients with type 2 diabetes. Diabetes 56, 1905-1912. 